\title{
Accuracy of the Anatomic Placement in Ultrasonography Guided Facet Joint Blockage with Supervising of C-Arm Fluoroscopy
}

\author{
Sinan Erdogan (iD) ${ }^{1}$, Sibel Caglar Okur (iD) ${ }^{2}$, Aysegul Atici (iD ${ }^{3}$, Huseyin Bahadir Gokcen (iD) ${ }^{1}$, Barış Polat \\ (iD) ${ }^{4,}{ }^{*}$ and Yunus Atici (iD ${ }^{5}$ \\ ${ }^{1}$ Department of Orthopedics and Traumatology, Istinye University Medical Faculty, Istanbul, Turkey \\ ${ }^{2}$ Department of Physical Therapy and Rehabilitation, Bakırkoy Dr. Sadi Konuk Research and Training Hospital, Istanbul, Turkey \\ ${ }^{3}$ Department of Physical Therapy and Rehabilitation, Kartal Training and Research Hospital, Istanbul, Turkey \\ ${ }^{4}$ Department of Orthopedics and Traumatology, Kyrenia University Medical Faculty, Kyrenia, Cyprus \\ ${ }^{5}$ Department of Orthopedics and Traumatology, Okan University Medical Faculty, Istanbul, Turkey \\ "Corresponding author: Department of Orthopedics and Traumatology, Kyrenia University Medical Faculty, Sehit Yahya Bakır St., Kyrenia, Cyprus. Tel: +90-5338444755, Email: \\ drbpolat@hotmail.com
}

Received 2018 September 18; Revised 2019 January 16; Accepted 2019 January 26.

\begin{abstract}
Background: Facet joint blockage is a type of regional anesthesia which is performed selectively on the medial branch of the ramus dorsalis of the spinal nerve and is a current approach for the treatment of pain originating from facet arthropathy. This current approach to chronic low back pain caused by facet joint pathology is usually performed with ultrasound guidance.

objectives: The accuracy of anatomical placement of the facet joint with ultrasonography guidance is determined by C-arm fluoroscopy image taken as reference.

Patients and Methods: A total of 22 patients who were diagnosed with facet joint syndrome were involved in the study. After detecting the superolateral corner of the facet joint, which is the target point with ultrasound, the control was provided with C-arm fluoroscopy by giving radiopaque fluid. In order to verify the localization, a mixture of $40 \mathrm{mg}$ triamcinolone and $1 \mathrm{cc} 2 \%$ lidocaine was injected.

Results: Nerve blockage was applied to 67 facet joints at L3 - L4, L4 - L5 and L5 - S1 level in a total of 22 patients (15 female and seven male) diagnosed with facet joint syndrome. The patients' mean age was 63 (range, 48 - 80), the mean body mass index was 28.4 (range, 18.9 -38.1) and the mean time to determine facet localization with ultrasonography (USG) was 240 seconds (range, 140 - 320). Patients' mean visual analog scale (VAS) decreased from 7 (range, 6 - 9) to 2.5 (range, 1 - 6). In the C-arm fluoroscopy control after the injection of radio-opaque material, the needle was found to be located in the lamina in four segments and it was relocated. In addition to this, two facet joints were not localized in ultrasound. This study concluded that the location of the facet joint with USG guidance is possible with $91 \%$ sensitivity and $100 \%$ positive predictive value when C-arm fluoroscopy was regarded as a gold standard in determining facet joint localization. No complications were observed.

Conclusion: The results showed that ultrasonography guided facet joint block can be considered as a minimally invasive procedure that could be easily applied without radiation exposure.
\end{abstract}

Keywords: Facet Joint Blockage, Ultrasonography, Fluoroscopy, Low Back Pain

\section{Background}

Chronic low back pain could result from the lumbar facet or zygapophyseal joints (1). Pain originating from the facet joint could cause pain that spreads to the lower back, hips and proximal lower extremity, inguinal region and posterior thigh. Furthermore, it may cause paravertebral sensitivity resulting in pseudoradicular pain (2).

Clinical diagnosis of facet joint syndrome is made by excluding other possible reasons for the pain (3-5). Facet joint syndrome is characterized by an increase in back pain during movements that irritates the facet joints and is the cause of pseudoradicular pain in the hips, posterior thigh or inguinal region (2).

Nonsteroidal anti-inflammatory drugs (NSAID), electrotherapy (ultrasound, transcutaneous electrical nerve stimulation [TENS], and fluid therapy), facet joint ablation, radiofrequency (RF), facet joint injection and neurotomy (on the medial branch of the ramus dorsalis) are the treatment options for facet joint syndrome (6). Facet joint injection in spinal surgery is a common method for presurgery diagnosis and the treatment of facet joint syndrome. Facet joint blockage may also be used to decide on dynamic or 
rigid segmental stabilization (7). Facet joint blockage is a type of regional anesthesia which is performed selectively on the medial branch of the ramus dorsalis of the spinal nerve and is a current approach for the treatment of pain originating from facet arthropathy (6).

\section{Objectives}

The purpose of the current study was to determine the accuracy of the anatomic placement of facet joint blockage performed with ultrasonography with the reference of Carm fluoroscopy.

\section{Patients and Methods}

\subsection{Study Design and Patient Selection}

We obtained ethical approval for this study from the Institutional Review Board of our hospital with the registration number of RY-2018-09. All the patients signed the informed consent form. Patients with chronic low back pain were evaluated. The criteria for inclusion in the study were age of $>18$ years, no radiculopathy findings, paravertebral muscle strain, pain in lateral flexion and lumbar hyperextension. Patients with local or systemic infection, who were allergic to steroids or lidocaine and/or who demonstrated findings other than facet joint arthrosis on MRI were excluded from the study. A total of 22 patients (seven males and 15 females) who were diagnosed with facet joint syndrome at L3 - L4, L4 - L5 and L5 - S1 levels were included in the study. Their mean age was 63 years (range, 48-80). The diagnosis of the patients was made by examination and radiography (lumbar anteroposterior, lateral and oblique $\mathrm{x}$ rays). The patients had more hypertrophy of the L3 - L4, L4 - L5 and L5 - S1 facets. When drug treatment and physical examination (about 3 months) failed in the patients, facet joint blockage was performed.

\subsection{Procedure}

The facet joint blockage was performed under sterile conditions in an operating theatre with the patient in a prone position. The iliac crest, lumbar spinous processes and presumed injection points were located with palpation and marked. Local anesthesia (lidocaine hydrochloride) was applied to the region before the intervention. The spinous processes were found in the longitudinal axis using a $5 \mathrm{MHz}$ convex transducer (Esaote MyLab 5). The facet joints were then located at a depth of $40-50 \mathrm{~mm}$ by shifting the transducer $2-2.5 \mathrm{~cm}$ laterally. When detecting the facet level in the practice segment, the transducer was adjusted to the transverse position so that the spinous process and facet joint transverse processes were imaged at the same time. Using the in-plane technique, at $1 \mathrm{~cm}$ lateral of the transducer, a 21 Gauge injector containing $0.5 \mathrm{~mL}$ radio-opaque agent (ioheksol) was inserted through the skin at an angle of $15^{\circ}-20^{\circ}$ (Figure 1 ). After detection of the superolateral corner of the facet joint as the target point, the radio opaque substance was administered and checked with a C-arm fluoroscopy (Figure 2). After verifying the localization, a mixture of $40 \mathrm{mg}$ triamcinolone and $1 \mathrm{cc} 2 \%$ lidocaine was injected. The patients were discharged after the procedure on the same day.

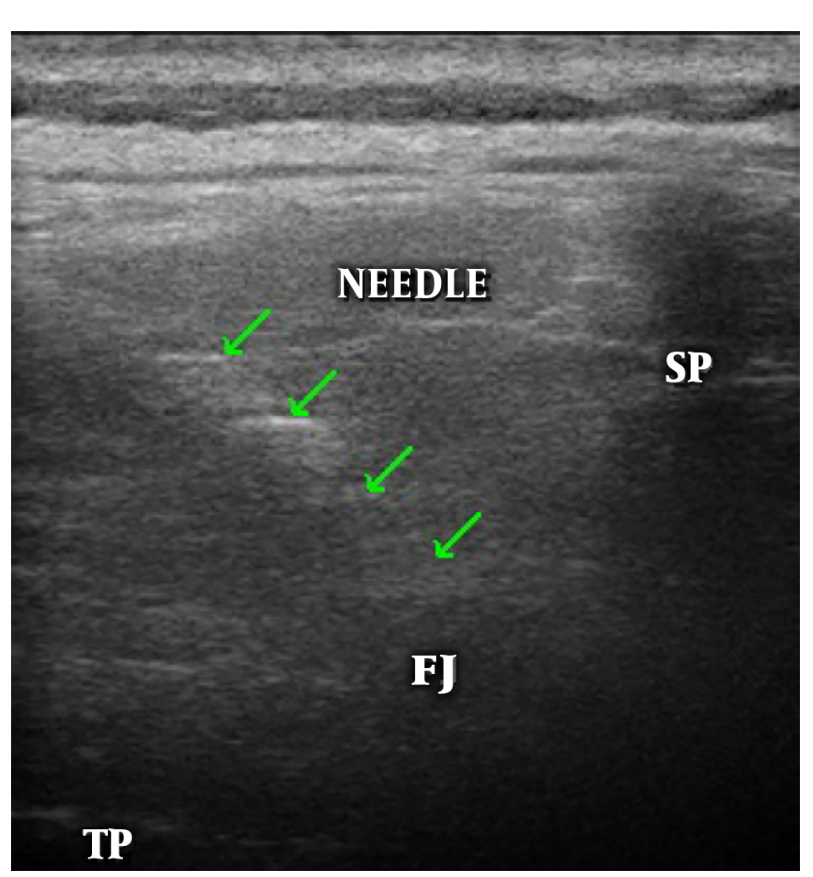

Figure 1. Ultrasound guided injection. FJ, facet joint; SP, spinous process; TP, transverse processes.

\subsection{Data Analysis}

Mean, standard deviation, median lowest, highest, frequency and ratio values were used in the descriptive statistics of the data. The distribution of the variables was measured by the Kolmogorov-Simirnov test. Wilcoxon test was used in the analysis of the dependent quantitative data. SPSS 22.0 (IBM Corp., Released 2013, IBM SPSS Statistics for Windows, Ver. 22, Armonk, NY, USA) was used for analyses.

\section{Results}

Nerve blockage was applied to 67 facet joints at the L3 - L4, L4 - L5 and L5 - S1 levels in a total of 22 patients diagnosed with facet joint syndrome. Patients mean age was 63 (range, 48 - 80), the mean body mass index was 28.4 


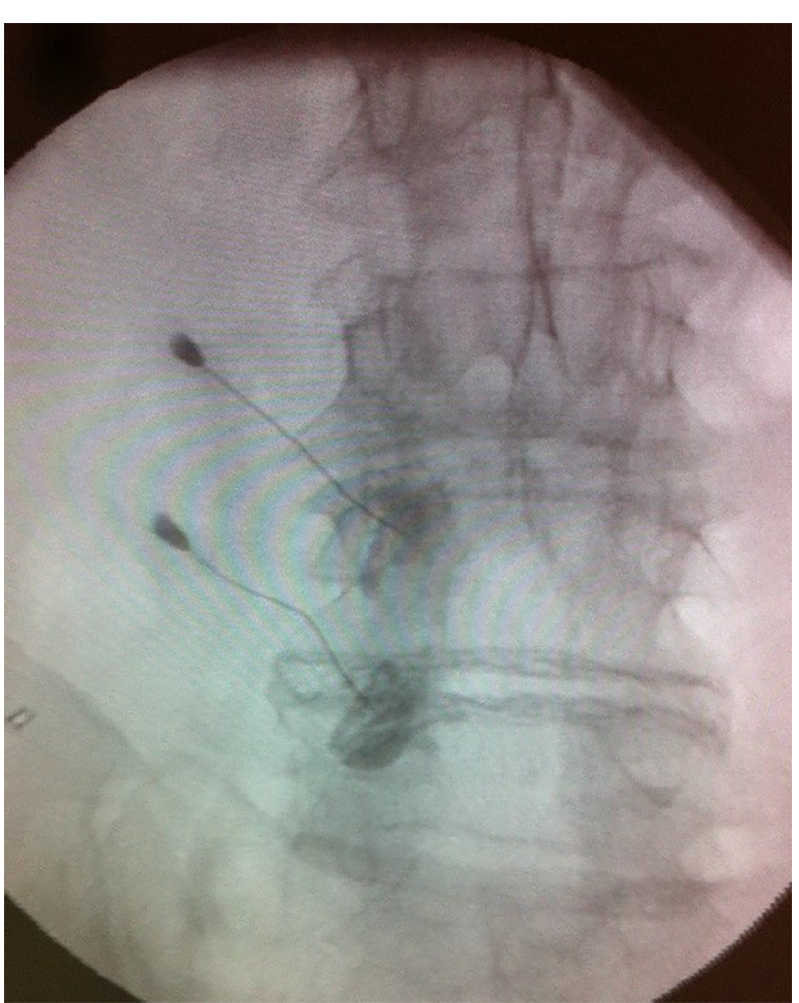

Figure 2. Control of facet joint with contrast agent in fluoroscopy (range, 18.9 - 38.1), the mean symptoms duration time was 18 months (range, 12 - 36) and the mean time to determine facet localization with USG was 240 seconds (range, 140 320). The lumbar facet nerve block was performed on 23 at the L3 - L4 level, 32 at the L4 - L5 level and 12 at the L5 - S1 level (Table1). Successful USG imaging was obtained at 61 of the 67 segments (Table 2). The facet joints could not be detected with USG in one patients 2 levels due to morbid obesity (body mass index [BMI]:38,1). In the C-arm fluoroscopy control after the injection of radio opaque material, the needle was found to be located in the lamina in 4 segments and it was relocated. Therefore, we corrected four faulty locations. Patients mean visual analog scale (VAS) decreased from 7 (range, 6-9) to 2.5 (range, 1 - 6) at the minimum 3 day after the procedure in the outpatient clinic (Table 3 ). This study concluded that the location of the facet joint with USG guidance is possible with $91 \%$ sensitivity and $100 \%$ positive predictive value. It took $235.9 \pm 56.1$ seconds to detect facet joint localization with the USG probe. No complications were observed.

\section{Discussion}

Apart from the pain originating from the facet joint, situations that could cause pathological pain such as tumor, infection, disc herniation and vertebral fracture must be eliminated through detailed clinical and radiological assessments $(8,9)$. Low back pain detected as facet joint arthrosis through imaging methods that does not respond to symptomatic treatment and has been ongoing for 6 months, constitutes the main indication for facet joint blockage. However, it is contraindicated in systemic infection, allergy (to steroid or local anesthetic), coagulopathy or pregnancy $(9,10)$. In the examination, pain typically intensifies with flexion and extension, and decreases with contralateral flexion and spinal flexion. While facet joint injections can be used as a treatment method for low back pain, it can also be used for diagnosis to determine whether or not the pain originates from the facet joint (10).

C-arm fluoroscopy is a method that facilitates the accurate application of facet joint blockage and enhances the treatment success rate and clinical effect (11). However, there is the disadvantage that both the patient and practitioner are exposed to radiation, which has been well documented in the literature to enhance the risk of cancer and damage to the skin, muscles and the eye lens (12). The main advantage of ultrasonography over C-arm fluoroscopy is that it does not involve radiation. The mobility of the device and the relatively low cost are other advantages (13). The disadvantage of ultrasound is that it is a technician-dependent method that requires experience. Only four facet joint levels were misplaced and two facet levels were not localized by ultrason in four different patients. The mean BMI of all 22 patients' was 28.4 , while in these four patients, the mean BMI was 33.6. These findings suggest that the elevation of BMI reduces the effectiveness of ultrasonography in determining facet joint localization.

In a CT-controlled cadaver study to assess the reliability of USG, Galiano et al. noted that USG was both applicable and highly accurate (14). Using a probe with an accurate frequency and with placement in the accurate localization, the target tissue could be seen clearly in a few seconds and moreover, vascular formations in the injection area could be eliminated with a simultaneous doppler signal to ensure that the target tissue is reached safely. Additionally, USG makes the practice possible without exposing the patients or physicians to radiation, which can damage skin, bones, parathyroid glands and lungs. After repeated applications, pigmentation in the nails and hands has been reported (15). Injection under USG guidance could be a preferred method in clinics, since it is practical and does not entail exposure to radiation.

In a study conducted by Yun et al., the time was cal- 


\begin{tabular}{|c|c|c|c|c|}
\hline & Min - Max & Median & Mean \pm SD & $\%$ \\
\hline Age & $48-80$ & 63.0 & $62.5 \pm 8.2$ & \\
\hline BMI & $18.9-38.1$ & 28.4 & $27.6 \pm 4.6$ & \\
\hline $\begin{array}{l}\text { Time to determine localization with } \\
\text { USG, second }\end{array}$ & $140-320$ & 240.0 & $235.9 \pm 56.1$ & \\
\hline Symptoms duration, month & $12-36$ & 18.0 & $20.2 \pm 8.0$ & \\
\hline \multicolumn{5}{|l|}{ Gender } \\
\hline Female & & & 15 & 68.2 \\
\hline Male & & & 7 & 31.8 \\
\hline \multicolumn{5}{|l|}{ L3 - L4 } \\
\hline Right & & & 5 & 7.4 \\
\hline Left & & & 2 & 2.9 \\
\hline Bilateral & & & 8 & 23.8 \\
\hline \multicolumn{5}{|l|}{ L4 - I5 } \\
\hline Right & & & 4 & 5.9 \\
\hline Left & & & 2 & 2.9 \\
\hline Bilateral & & & 13 & 38.8 \\
\hline \multicolumn{5}{|l|}{ L5 - S1 } \\
\hline Right & & & 3 & 4.4 \\
\hline Left & & & 1 & 1.4 \\
\hline Bilateral & & & 4 & 11.9 \\
\hline
\end{tabular}

Abbreviations: BMI, body mass index; SD, standard deviation; USG, ultrasonography.

\begin{tabular}{|c|c|c|c|c|}
\hline & \multicolumn{2}{|c|}{ C-arm (skopi) } & \multirow{2}{*}{ Sensitivity } & \multirow{2}{*}{$\begin{array}{c}\text { Positive } \\
\text { predictive } \\
\text { value }\end{array}$} \\
\hline & $(+)$ & $(-)$ & & \\
\hline USG & & & $91.0 \%$ & $100.0 \%$ \\
\hline
\end{tabular}

\begin{tabular}{lll}
$(+)$ & 61 & 0 \\
$(-)$ & 6 & 0 \\
\hline
\end{tabular}

Abbreviation: USG, ultrasonography.

Table 3. Patients' VAS Values Before and After Procedure

\begin{tabular}{cccccc}
\hline & Min-Max & Median & Mean \pm SD & P value \\
\hline VAS & & & & & $<0.000^{\mathrm{a}}$ \\
& Preoperation & $6.0-9.0$ & 7.0 & $7.2 \pm 0.9$ & \\
& Postoperation & $1.0-6.0$ & 2.5 & $2.9 \pm 1.4$ & \\
\hline
\end{tabular}

Abbreviations: SD, standard deviation; VAS, visual analog scale. ${ }^{\mathrm{a}}$ Wilcoxon test.

culated between prone positioning of the patient and injection, under the guidance of USG or C-arm fluoroscopy. The duration of using C-arm fluoroscopy was $248.7 \pm 6.5$ seconds, whereas with USG, it was determined as $263.4 \pm$
5.9 seconds (2). However, those durations did not include preparation procedures and when the C-arm equipment preparation time was taken into consideration, USG guidance was seen to be more advantageous in terms of time. Nevertheless, the duration depends on the experience of the person. Although complications are rarely seen in facet joint blockage, they may be observed while placing the needle and giving the medication. These complications include bleeding related or unrelated to the intravascular entry, infection, dural injury, spinal anesthesia, neural trauma, spinal cord trauma, pneumothorax, exposure to radiation, hematoma and side effects related to steroids. In ultrasonography, the ability to visualize the vascular formation with Doppler decreases the risk of complications, which may occur as a result of intravascular entry (16-20). No complications occurred in our patients.

Although facet joint blockage for low back pain is a simple, reliable and cost-effective technique, most previous studies have been noncontrolled group studies $(21,22)$.

The limitations of the current study are that the patient group was small and the procedure was limited to L3 - L4, L4 - L5 and L5 - S1 levels. It should be considered that facet joints are vertical and imaging with USG may be more dif- 
ficult at upper levels of the spine.

In this study, reliability of USG was compared with Carm fluoroscopy and the results demonstrated that ultrasonography is as effective as C-arm fluoroscopy in locating the joint. USG can be considered to be a more practical and effective method than C-arm fluoroscopy for facet injections in clinics.

\section{Footnotes}

Authors' Contributions: Study concept and design: Sinan Erdogan, Sibel Caglar Okur and Aysegul Atici; acquisition of data: Sinan Erdogan and Huseyin Bahadir Gokcen; analysis and interpretation of data: Barış Polat and Yunus Atici; drafting of the manuscript: Sinan Erdogan, Barış Polat and Yunus Atici; critical revision of the manuscript for important intellectual content: Huseyin Bahadir Gokcen, Barıș Polat and Yunus Atici; statistical analysis: Sinan Erdogan and Barış Polat

Conflict of Interests: The authors report no conflict of interests.

Ethical Approval: Institutional Review Board approval was obtained.

Financial Disclosure: It is not declared by the authors. Funding/Support: It is not declared by the authors.

\section{References}

1. Boswell MV, Colson JD, Spillane WF. Therapeutic facet joint interventions in chronic spinal pain: A systematic review of effectiveness and complications. Pain Physician. 2005;8(1):101-14. [PubMed:16850048].

2. Yun DH, Kim HS, Yoo SD, Kim DH, Chon JM, Choi SH, et al. Efficacy of ultrasonography-guided injections in patients with facet syndrome of the low lumbar spine. Ann Rehabil Med. 2012;36(1):66-71. doi: 10.5535/arm.2012.36.1.66. [PubMed: 22506237]. [PubMed Central: PMC3309334].

3. Cohen SP, Huang JH, Brummett C. Facet joint pain-advances in patient selection and treatment. Nat Rev Rheumatol.2013;9(2):101-16. doi: 10.1038/nrrheum.2012.198. [PubMed: 23165358].

4. Maas ET, Juch JN, Ostelo RW, Groeneweg JG, Kallewaard JW, Koes BW, et al. Systematic review of patient history and physical examination to diagnose chronic low back pain originating from the facet joints. Eur J Pain. 2017;21(3):403-14. doi: 10.1002/ejp.963. [PubMed: 27723170].

5. Vekaria R, Bhatt R, Ellard DR, Henschke N, Underwood M, Sandhu H. Intra-articular facet joint injections for low back pain: A systematic review. Eur Spine J. 2016;25(4):1266-81. doi: 10.1007/s00586-016-4455-y. [PubMed: 26906169].

6. Sehgal N, Shah RV, McKenzie-Brown AM, Everett CR. Diagnostic utility of facet (zygapophysial) joint injections in chronic spinal pain: A systematic review of evidence. Pain Physician. 2005;8(2):211-24.

7. Fritz J, Sequeiros RB, Carrino JA. Magnetic resonance imagingguided spine injections. Top Magn Reson Imaging. 2011;22(4):143-51. doi: 10.1097/RMR.ob013e31827e5de1. [PubMed: 23514922].
8. Jung H, Jeon S, Ahn S, Kim M, Choi Y. The validation of ultrasoundguided lumbar facet nerve blocks as confirmed by fluoroscopy. Asian Spine J. 2012;6(3):163-7. doi: 10.4184/asj.2012.6.3.163. [PubMed: 22977695]. [PubMed Central: PMC3429606].

9. Ha DH, Shim DM, Kim TK, Kim YM, Choi SS. Comparison of ultrasonography-and fluoroscopy-guided facet joint block in the lumbar spine. Asian Spine J. 2010;4(1):15-22. doi: 10.4184/asj.2010.4.1.15. [PubMed: 20622950]. [PubMed Central: PMC2900164].

10. Yoon SH, O'Brien SL, Tran M. Ultrasound guided spine injections: Advancement over fluoroscopic guidance? Curr Phys Med Rehabil Rep. 2013;1(2):104-13. doi: 10.1007/s40141-013-0016-z.

11. Bogduk N. International Spinal Injection Society guidelines for the performance of spinal injection procedures. Part 1: Zygapophysial joint blocks. Clin J Pain. 1997;13(4):285-302. doi: 10.1097/00002508199712000-00004. [PubMed: 9430809].

12. Zhou Y, Singh N, Abdi S, Wu J, Crawford J, Furgang FA. Fluoroscopy radiation safety for spine interventional pain procedures in university teaching hospitals. Pain Physician. 2005;8(1):49-53. [PubMed: 16850042].

13. Greher M, Kapral S. Is regional anesthesia simply an exercise in applied sonoanatomy?: Aiming at higher frequencies of ultrasonographic imaging. Anesthesiology. 2003;99(2):250-1. doi: 10.1097/00000542-200308000-00004. [PubMed: 12883395].

14. Galiano K, Obwegeser AA, Bodner G, Freund M, Maurer H, Kamelger FS, et al. Ultrasound guidance for facet joint injections in the lumbar spine: A computed tomography-controlled feasibility study. Anesth Analg. 2005;101(2):579-83. table of contents. doi: 10.1213/01.ANE.0000158609.64417.93. [PubMed: 16037179].

15. Wagner LK, Eifel PJ, Geise RA. Potential biological effects following high X-ray dose interventional procedures. J Vasc Interv Radiol. 1994;5(1):71-84. doi: 10.1016/S1051-0443(94)71456-1. [PubMed: 8136601].

16. Manchikanti L, Malla Y, Wargo BW, Cash KA, Pampati V, Fellows B. Complications of fluoroscopically directed facet joint nerve blocks: A prospective evaluation of 7,500 episodes with 43,000 nerve blocks. Pain Physician. 2012;15(2):E143-50. [PubMed: 22430660].

17. Staal JB, de Bie RA, de Vet HC, Hildebrandt J, Nelemans P. Injection therapy for subacute and chronic low back pain: An updated Cochrane review. Spine (Phila Pa 1976). 2009;34(1):49-59. doi: 10.1097/BRS.ob013e3181909558. [PubMed: 19127161].

18. Manchikanti L, Boswell MV, Singh V. Comprehensive evidence-based guidelines for interventional techniques in the management of chronic spinal pain. Pain Physician. 2009;12:699-802.

19. Atluri S, Datta S, Falco FJ, Lee M. Systematic review of diagnostic utility and therapeutic effectiveness of thoracic facet joint interventions. Pain Physician. 2008;11(5):611-29. [PubMed: 18850026].

20. Lee CJ, Kim YC, Shin JH, Nahm FS, Lee HM, Choi YS, et al. Intravascular injection in lumbar medial branch block: A prospective evaluation of 1433 injections. Anesth Analg. 2008;106(4):1274-8. table of contents. doi: 10.1213/ane.0b013e318162c358. [PubMed: 18349205].

21. Schneider B, Levin J. A narrative review of intra-articular zygapophysial steroid injections for lumbar zygapophysial-mediated pain. Curr Phys Med Rehabil Rep. 2016;4(2):108-16. doi: 10.1007/s40141016-0117-6.

22. Wu T, Zhao WH, Dong Y, Song HX, Li JH. Effectiveness of ultrasoundguided versus fluoroscopy or computed tomography scanning guidance in lumbar facet joint injections in adults with facet joint syndrome: A meta-analysis of controlled trials. Arch Phys Med Rehabil. 2016;97(9):1558-63. doi: 10.1016/j.apmr.2015.11.013. [PubMed: 26705882]. 